\title{
AN EPIDEMIOLOGICAL STUDY OF CONGENITAL DEFORMITIES OF HAND AT A TERTIARY CARE HOSPITAL
}

\section{Orthopaedics}

Dr. Imran Khan Senior Resident, Department of Orthopaedics, Kolkata Medical College, Kolkata, India.

Dr. Anindya Basu* Assistant Professor, Department of Orthopaedics, Kolkata Medical College, Kolkata, India. *Corresponding Author

\begin{tabular}{ll}
\hline Dr. Biplab & Assistant Professor, Department of Orthopaedics, Burdwan Medical College, West \\
Chatterjee & Bengal, India.
\end{tabular}

Dr. Chinmay De Professor, Department of Orthopaedics, Burdwan Medical College, West Bengal, India.

\section{ABSTRACT}

Background: Congenital deformities of hand encompass a myriad of deformities, all of which carry different functional \& cosmetic implications The most commonly encountered malformations of the hand are syndactyly, polydactyly, congenital absence, camptodactyly, clinodactyly \& radial club hand.

Aim: Our aim was to obtain a cross section of the epidemiology of congenital hand deformities and to be well adapted to help the parents \& the child, whenever possible, regarding rehabilitation \& surgical options for optimal functional outcome.

Settings \& Design: This was a cross-sectional study of 50 patient attending at a tertiary care hospital for the duration of one and half year.

Methods \& Materials: All the patients were examined clinically with detailed history including family history of similar anomalies. Clinical photographs were taken with due permission. Radiographs were obtained to confirm diagnoses.Functional assessment with the disabilities of arm, shoulder \& hand (DASH) outcome questionnaire was done whenever possible.

Stastical Analysis Used: This was an observation study. The results obtained were analyzed using charts \& diagrams.

Results: Total 50 cases recorded, 34 male \& 16 female. Polydactyly (8) \&symbrachydactyly (8) most commonly observed anomalies. Syndactyly (6) second most common anomaly.Anomalies were more commonly found on right side (23). Bilateral in 13 cases.Symbrachydactyly was more common in left in male patients. One male patient had bilateral trigger fingers \& trigger thumb. Most of the patients were below 15 years (45).

Conclusion: We may conclude that although rare, congenital deformities of hand include a wide variety of disorders.Actual incidence may be higher than observed. $10 \%$ patients have significant cosmetic or functional deficit. Most common disorder found in our institute is polydactyly \& symbrachydactyly. It is more common in boys.

\section{KEYWORDS}

congenital hand deformity, syndactyly, polydactyly, camptodactyly, clinodactyly \& radial club hand.

\section{INTRODUCTION}

Congenital anomalies affect 1 to $3 \%$ of newborns and approximately $10 \%$ of these children have upper extremity abnormalities. Congenital limb anomalies are second only to congenital heart disease in the incidence of birth malformations. ${ }^{3}$ Most anomalies occur spontaneously or are inherited. ${ }^{4}$ Few malformations are attributed to teratogens ${ }^{5,6,7}$

Congenital malformations of hand encompass a myriad of deformities, all of which carry different functional \& cosmetic implications for the patients \& parents. The most commonly encountered anomalies of the hand are syndactyly, polydactyly, congenital absence, camptodactyly, clinodactyly \& radial club hand. Isolated nongenetic defects include unilateral transverse failure of formation, defects due to constriction bands, longitudinal radial \& ulnar dysplasias, macrodactyly\& preaxial polydactyly. Isolated autosomal dominant deformities include lobster claw deformity, symphalangism, brachydactyly, triphalangeal thumb, camptodactyly\& postaxial polydactyly. Syndactyly may occur sporadically or as a dominant trait ${ }^{8,9}$. Approximately $10 \%$ of the patients with congenital hand deformities have significant cosmetic \& functional deficits. Up to two thirds of the patients of congenital hand deformities have additional birth defects ${ }^{10,11,12}$. The American Society for Surgery of the Hand \& the International Federation of Societies for Surgery of the Hand accept the classification system devised by Swanson, Barsky \&Entin which divides congenital deformities of hand into seven categories viz.

1. Failure of formation

- Transverse arrest

- Longitudinal arrest

2. Failure of differentiation (separation) of parts

- Soft tissue involvement

- Skeletal involvement

3. Duplication

4. Overgrowth

5. Undergrowth

6. Constriction ring syndrome

7. Generalized abnormalities \& syndromes
This classification does not delineate etiological factors, treatment, prognosis, \& there is ongoing work for further revision of the system ${ }^{20}$.

\section{MATERIALS AND METHOD}

An institution based, prospective, non-interventional, observation study was conducted of 50 patients attending the Orthopaedics OPD,Paediatrics OPD, Disability boards at a tertiary care hospital over a period of one and half years from January 2017 to September 2018.

Inclusion Criteria: Patients with congenital deformities of hand.

Exclusion Criteria: Patients with acquired hand deformities

Patients with neurological abnormalities.

Patients with congenital hand anomalies were added to the study after obtaining written informed consent. Data was collected in a simple format with two parts viz. patient particulars \& disease details.

After getting approval from the Institutional Ethical Committee patients fulfilling the inclusion criteria were added to the study group on getting written informed consent. All the patients were examined clinically with detailed history including family history of similar anomalies. Clinical photographs were taken with due permission. Radiographs were obtained to confirm diagnoses particularly in radial\& ulnar ray defects. Any suspected syndromic patient was referred to paediatric OPD for opinion \& further work up as necessary. Functional assessment with $\mathrm{DASH}^{13}$ scoring system was done when possible.

The data collected was analyzed to draw an inference regarding cross section of the epidemiology of congenital deformities of hand at our institute during the study period.

\section{RESULTS \& ANALYSIS}

Total 50 cases recorded, 34 male \& 16 females. Polydactyly (eight) \& symbrachydactyly (eight) most commonly observed anomalies. Syndactyly (six) second most common anomaly. Anomalies more commonly found on right side (23). Bilateral in 13 cases. Symbrachydactyly was more common in left in male patients. One 
male patient had bilateral trigger fingers \& trigger thumb. Most of the patients were below 15 years (45). DASH scoring was done in 8 cases. Polydactyly is the most common deformity observed along with symbrachydactyly. Equally distributed in male \& females. No specific side preponderance. Included deformities like bifid thumb \& mirror hand.There was family history of polydactyly in three cases. DASH functional scoring was done in two cases \& results were $11.7 \& 10.8$

Total eight cases of Symbrachydactylywere observed. Among them seven are male, one female.Left side predominance observed in male patients.DASH scoring done in one case (39.2).In one patient there was brachydactyly in opposite hand

Six cases of Syndactylywere observed,three male \& three females.Bilateral involvement seen in two cases.In a female patient there was syndactyly of toes, hypercalcaemia \& history of seizure disorder (syndromic).Family history of syndactyly in a bilateral case.

Five cases of Clinodactyly were observed.Four male \& one females.Right side predominance seen.DASH scoring done in one case (9.2).

Four cases ofCamptodactylywere observed, Three male \& one females.Bilateral involvement seen in two case.In one baby with bilateral involvement, bilateral congenital talipes equinovarus (CTEV) was seen. There was also family history of CTEV.DASH functional scoring was done in one case (19.2)

Two cases of Trigger Fingerwere observed.No female patients in our study.Bilateral involvement seen in one case.In one patient there was bilateral trigger fingers \& thumb. DASH score was (71.7).

Three cases of Trigger Thumb were observed. Two male \& one female. Bilateral involvement seen in one male with bilateral trigger fingers. DASH score (71.7).

Two cases of Radial Club Hand were observed. One male \& one female. Bilateral involvement in male baby. The baby had congenital heart disease (syndromic).In the female baby there was bilateral CTEV.

Total Four cases of Cleft Hand were observed. Three male, one female. Bilateral involvement seen in one case along with bilateral cleft feet. DASH scoring was done in two cases $(65.8 \& 67.5)$.

Four cases of Ulnar Dysplasia were observed, Three male \& one female. Bilateral Involvement in one male baby. In all cases there was elbow involvement (fused or unstable) on the same side with absent digits \& thumb. In a bilateral involvement there was right tibial hemimelia also.

Arthrogryposis Multiplex CongenitaFour cases observed. Two male \& twofemale. Bilateral involvement in all four cases.In all cases there was involvement of two or more joints in the body particularly elbow, shoulder \& hip.

\section{DISCUSSION}

Congenital anomaly of hand includes a wide spectrum of disorders. It is relatively uncommon but the actual incidence may be higher in general population as minor deformities do not seek treatment. Some of the patients included in this study sought treatment for other conditions \& were incidentally discovered to having hand anomalies from birth. Population based studies on congenital hand deformities in literature found higher incidence than that estimated by studies on patients seeking treatment. ${ }^{1,1,8}$

Congenital anomaly of hand is more common in boys. In our study anomalies were found mostly on the right side except in symbrachydactyly where left side predominance was seen in male patients. In literature no evidence of side preponderance is found. ${ }^{8.14,15}$, 18,19 Bilateral anomalies are found in about $25 \%$ cases. Non hand anomalies are found in about $22 \%$ cases, mostly in the lower limbs $(18 \%)$. In $10 \%$ cases there is known occurrence in relatives. This data corroborates with the population studies in Stockholm ${ }^{15}$, Edinburgh ${ }^{14} \&$ Western Australia ${ }^{8}$ Syndromic associations included Holt Oram syndrome (radial club hand with congenital heart disease), Barakat syndrome (hypoparathyroidism, sensorineural deafness, renal disease) with syndactyly of fingers \& toes.
The most commonly observed congenital anomaly in our study was symbrachydactyly\& polydactyly. Occurrence was sporadic or as a dominant trait. Polydactyly included deformities like bifid thumb \& a very rare anomaly, mirror hand. Other common anomalies included syndactyly, clinodactyly, camptodactyly, ulnar dysplasia, arthrogryposis multiplex congenita, trigger fingers \& thumb \&radial club hand. In most of thepopulation or institute based studies in literature, syndactyly or polydactyly is the most common congenital anomaly of hand. ${ }^{8,14,15,1,19}$ A population based study, "Congenital upper limb deficiencies and associated malformations", conducted in Finland $^{12}$ by Koskimies E, Lindfors N, Gissler M, et al had similar observations. Comparable results are found in other studies also., ${ }^{8,14,15,18,19}$

\section{CONCLUSION}

The intention of this study was to evaluate the cross section of epidemiology of congenital deformities of hand at our institute for one $\&$ a half years.

Although rare, congenital anomalies of hand include a wide variety of disorders. Significant cosmetic \& functional disability is seen only in $10 \%$ cases. The actual incidence may be higher in population as patients with minor deformities do not seek treatment. Most of the patients included in our study either visited for disability certificate or were incidentally discovered while seeking treatment for other condition.

It is more common in boys. Approximately one third of the patients have bilateral involvement. About $15 \%$ patients have associated non hand anomalies, most commonly involving the lower limb. In $11 \%$ cases there is positive family history.

Polydactyly, symbrachydactyly, syndactyly, clinodactyly, camptodactyly, trigger fingers \& thumb, radial club hand, ulnar dysplasia \& arthrogryposis multiplex congenita was observed

We may conclude that although rare, congenital deformities of hand include a wide variety of disorders

- Actual incidence may be higher than observed.

- $10 \%$ patients have significant cosmetic or functional deficit

- Most common disorder found in our institute is polydactyly \&symbrachydactyly.It is more common in boys.

- There is slight right side preponderance.Bilateral involvement is seen in about one fifth cases.

- Associated anomalies seen in $15 \%$ cases \& mostly involvesthe lower limbs.

- Positive family history is seen in $11 \%$ cases.

\section{REFERENCES}

1. Flatt A: The care of congenital hand anomalies, St. Louis, 1994, Quality Medical Publishing.

2. Parker SE, Mai CT Canfield MA et al: Updated National Birth Prevalence estimates for selected birth defects in the United States, 2004-2006. Birth Defects Res A Clin Mol Teratol 88:1008, 2010.

3. Bamshad M, Watkins WS, Dixon ME, et al: Reconstructing the history of human limb development: lessons from birth defects. Pediatr Res 45:291, 1999.

4. Temtamy SA, McKusick VA: The genetics of hand malformations. Birth Defects Orig Artic Ser 14:1, 1978.

5. Kato H, Ogino T, Minami A, et al: Experimental study of radial ray deficiency. J Hand Surg [Br] 15:470, 1990

Ogino T, Kato H: Clinical and experimental studies on ulnar ray deficiency. HandchirMikrochirPlastChir 20:330, 1988.

Taussig HB: A study of the German outbreak of phocomelia. The thalidomide syndrome. JAMA 180:1106, 1962

8. Giele $H$, Giele C, Bower C, Allison M. The incidence and epidemiology of congenital Giele H, Giele C, Bower C, Allison M. The incidence and epidemiology of congenital
upper limb anomalies: a total population study. JHand Surg Am. 2001 Jul. 26(4):628-34. upper limb anomalies: atotal population study. J Hand Surg Am. 2001 Jul. 26(4):628-34.
Kozin SH: Current concepts review: upper-extremity congenital anomalies, J Bone Joint Surg 85A:1564, 2003

10. Wynne-Davies R, Kuczynski K, Lamb DW, et al: Congenital abnormalities of the hand. In Lamb DW, Hooper G, Kuczynski K, editors: The practice of hand surgery, ed 2, Oxford, 1989, Blackwell Scientific.

II. Wynne-Davies $R$, Lamb DW: Congenital upper limb anomalies: an etiologic grouping of clinical, genetic, and epidemiologic duta from 382 patients with "absence" defects, constriction bands, polydactylies, and syndactlies, JHand Surg Am A: 958, 1985.

12. Koskimies $E$, Lindfors $N$ Gissler $M$ et al: Congenital upper limb deficiencies and associated malformations in Finland: a population based study, JHand Surg 36A:1058, 2011.

13. Atroshi I, Gummesson C, Andersson B, Dahlgren E, Johansson A. The disabilities of the arm, shoulder and hand (DASH) outcome questionnaire: reliability and validity of the Swedish version evaluated in 176 patients. Acta OrthopScand 2000; 71:413-618

14. Rogala EJ, Wynne-Davies R, Littlejohn A, Gormley J. Congenital limb anomalies:frequency and aetiological factors. Data from the Edinburgh Register of the Newborn (1964-68). J Med Genet. 1974 Sep. 11(3):221-33.

15. Ekblom AG, Laurell T, Arner M. Epidemiology of congenital upper limb anomalies in 562 children born in 1997 to 2007: a total population study from Stockholm. Sweden. Hand Surg Am. 2010 Nov 35(11):1742-54.

16. Bowe J, Conway H. Congenital deformities of the hands. PlastReconstr Surg. 1956 Oct 8(4): $286-90$

17. Lamb DW, Wynne-Davies $R$, Soto L. An estimate of the population frequency of congenital malformations of the upper limb. JHand Surg Am. 1982 Nov. 7(6):557-62. 
18. Goldfarb CA, Wall LB, Bohn DC, Moen P, Van Heest AE. Epidemiology of congenital upper limb anomalies in a midwest United States population: an assessment using the Oberg, Manske, and Tonkin classification.JHand Surg Am. 2015 Jan. 40 (I):127-32.el-2.

Ghorpade N, Goyal N, John J. Prevalence of musculoskeletal abnormalities in newborn: A 10 years retrospective analysis of 10,674 neonates in Indian population at a tertiary care hospital. J Clin Neonatol. 2015:4:104-8.

20. Gold NB, Westgate M-N, Holmes LB: Anatomic and etiological classification of congenital limb deficiencies, Am J Med Genet Part A 155:1225, 2011. 